\title{
Prevalence of Overweight and Obesity in Hispanic Preschool Children in San Luis Obispo County, California
}

\author{
Kristine Z. Jankovitz ${ }^{1}$, Karen J. McGaughey ${ }^{1}$, Kyla Tom ${ }^{1}$, Dayna Ravalin ${ }^{2}$, and Ann Yelmokas \\ McDermott $^{1}$ \\ ${ }^{1}$ California Polytechnic State University, San Luis Obispo, CA \\ ${ }^{2}$ San Luis Obispo County Public Health Department, CA
}

\begin{abstract}
The purpose of the study was to determine the prevalence of overweight and obese (OW/OB) preschool children in San Luis Obispo County. Preschool children ages 3-5 years were measured for height and weight in $2006(n=482)$ and in 2009/10 combined $(n=559)$. The CDC BMI calculator for ages 2-20 was used to determine BMI classification. In 2006, 26.4\% were OW/OB and by 2009/10, 34.8\% were OW/OB. Rates were similar among boys and girls $(\mathrm{p}=0.70)$ and increased significantly over time $(\mathrm{p}=$ 0.0070). Caucasian and Hispanic children had similar OW/OB rates in 2006, but by 2009/10 the Hispanic children were 2.7 times more likely to be obese (CI: 1.68, 4.57). Because Hispanic children were more likely to attend Head Start or California State preschools versus private preschools $(78.0 \%, 81.0 \%$ and 7.4\% respectively), it appears Head Start and California State preschools would be a likely place for interventions directed to meet the needs of Hispanic preschoolers, and may serve to reverse the trend in childhood obesity and address the disparity in weight status among Hispanic preschool aged children.
\end{abstract}

(C) 2012 Californian Journal of Health Promotion. All rights reserved.

Keywords: Obesity, overweight, preschool children, body mass index, disparity in weight status.

\section{Introduction}

The trend toward overweight and obesity during childhood has been labeled an obesity epidemic and the prevalence in the United States has tripled in the past thirty years (Ogden \& Carroll, 2010; U.S. Department of Health \& Human Services, 2011). The dramatic increase in obesity rates has become a public health crisis in part because early childhood overweight and obesity (OW/OB) have been found to be associated with OW/OB in adulthood (Brisbois, Farmer \& McCargar, 2011). Further, OW/OB in childhood is a threat to health among all age, ethnic and socio-economic groups and is linked to heart disease, diabetes, metabolic syndrome, asthma, kidney disease and other co-morbidities (Diamont, Babey, Wolstein \& Jones, 2010; Singh, Kogan \& van Dyck, 2010; Barton, Gilbert, Baramee \& Granger, 2006; Must, Spadano, Coakley, Field, Coldtiz, \& Dietz,
1999; Poirier et al., 2006). The available evidence suggests considerable ethnic/racial disparity in obesity rates in children with American Indian/Native Alaskans having the highest prevalence followed by Hispanic, Black non-Hispanic, White non-Hispanic, and Asians, and socioeconomic status has been shown to have an inverse relationship with obesity (Anderson \& Whitaker, 2009; Wang \& Beydoun, 2007).

With one in four 2-5 year olds in the United States being OW/OB the public health community has made it a priority to address this problem (Anderson \& Whitaker, 2009; Ogden \& Carroll, 2010). Healthy People 2020 provides several objectives to decrease the proportion of children ages 2-5 that are OW/OB and a wellknown effort to address the objectives in Healthy People 2020 to counter OW/OB in young children is Michelle Obama's priority 
initiative called "Lets' Move" (U.S. Department of Health \& Human Services Healthy People 2020, 2009; http://www.letsmove.gov).

In 2004 the San Luis Obispo County Public Health Department division of Maternal, Adolescent and Child Health (MCAH) joined 38 other counties in California to include an objective in the MCAH work plan to reduce the percentage of children over the $85^{\text {th }}$ percentile for BMI for age by $5 \%$ by 2009 . It was decided to focus on children ages 3-5 so as to target the time period of accelerated growth that occurs between 4 and 5 years of age. Due to limited available data on BMI in preschool aged children in San Luis Obispo (SLO) County, cross-sectional data were collected to determine the prevalence of $\mathrm{OW} / \mathrm{OB}$ in this population. In 2006, the prevalence of OW/OB preschool children in SLO County was consistent with the national rates and appeared to be rising in step with state and national trends (Tom, Rivera, Ravalin, \& Jankovitz, 2009).

\section{Purpose}

The prevalence of OW/OB in preschool children aged 3-5 years in SLO County was assessed in 2006, 2009 and 2010. The purpose of the study was to determine the rate of $\mathrm{OW} / \mathrm{OB}$ in preschool children in SLO County for each year and to identify if differences in weight status existed based on calendar year, gender, ethnicity, and type of preschool (public or private).

\section{Methods}

Each year the study included a cross-sectional convenience sample of private, California State, and Head Start preschools. Head Start preschools are federally funded programs for low-income families with an income eligibility of $130 \%$ or below of the federal poverty level (http://caheadstart.org/HSPrograms.html).

California State preschools are state funded programs for families with incomes at or below $75 \%$ of the state median income (http://www.first5slo.org). Private preschools are funded through tuition or fees and receive no direct federal or state funding, however some students may have partial funding for preschool through state childcare subsidies. In 2008 there were 65 licensed preschool centers in the county seven of which were Head Start and twelve were California State preschools (http://www.first5slo.org). In 2006 and 2009/10 combined almost $57 \%$ of preschools $(\mathrm{n}=37)$ participated in the study, including all Head Start and California State preschools. All preschools were invited to participate by the SLO County Public Health Department. Preschool directors chose to inform parents about the opportunity for their child to participate in the study by distributing copies of a letter from the Public Health Department, by providing information in the school newsletter, or through verbal requests from preschool staff members. Parents were provided an informed consent form requesting permission to measure their child's height and weight, and to obtain the child's age (in 2006) or date of birth (in 2009 and 2010) from the preschool teacher for the purpose of calculating body mass index. All forms of communication were provided in English and Spanish.

\section{Participants}

The population of SLO County $(\mathrm{n} \approx 262,000)$ is approximately $70 \%$ white, $19 \%$ Hispanic, 3\% Asian/Pacific Islander, 2\% African American, and $1 \%$ Native American and the remaining 5\% others (http://www.first5slo.org ). The 20052009 American Community Survey reported there were 4004 children enrolled in preschool in SLO County (U.S. Census Bureau, 2005-2009 American Community Survey). In 2006 and 2009/10 combined, approximately $25 \%$ of preschool children $(n=1041)$ in SLO County participated in the study. Participants were boys and girls, aged 3-5 years, attending preschool in SLO County in April and May of 2006, 2009 and 2010. Each year preschool sites that volunteered to participate were included if a date and time could be arranged for the physical assessments and if the preschool teacher(s) could provide the age (in 2006) or date of birth (in 2009 and 2010) for each child and information about race/ethnicity. Participants were identified as Hispanic if they had a Hispanic surname, if Spanish was spoken in the home or if Spanish was the primary language of at least one parent. Preschool children were 
included in the study if they had consent from a parent or guardian, attended preschool on the day of data collection, and only if they wanted to participate at the time the measures were being collected. Informed consent, provided in both English and Spanish, was obtained from the parents or guardians of the participating preschool children, and the California Polytechnic State University, San Luis Obispo Institutional Review Board approved the study.

\section{Measures}

In 2006, a registered dietician with the public health department and two trained graduate and undergraduate research assistants proficient in the use of standardized measurement protocols collected measures for height and weight. In 2009 and 2010, undergraduate and graduate research assistants proficient in standardized measurement protocols for height and weight in children collected measures. All research assistants in 2009 and 2010 completed Protection of Human Research Participants Certification from the National Institutes of Health.

Height. Height without shoes was measured by a portable stadiometer. The stadiometer was calibrated with a measuring tape starting at the zero point. Children were asked and assisted to remove any hats or hair accessories that could alter height measurement and were directed to stand with their back to the stadiometer, stepping as close as possible without touching it. As the child stood tall with feet together and arms by his or her side the headpiece of the stadiometer was moved to the crown of his or her head. Each child was measured three times to the nearest $0.1 \mathrm{~cm}$ and all measures were recorded. The two closest measurements within $0.3 \mathrm{~cm}$ were averaged during the data entry process. If there were no two measurements that were within $0.3 \mathrm{~cm}$, all three measurements were averaged.

Weight. Children were asked and assisted to remove shoes, jackets or sweatshirts prior to being weighed. A digital scale measured weight to the nearest $0.1 \mathrm{~kg}$. The digital scales were calibrated at each site with a 5 lbs. weight. Digital scales were zeroed after every measurement. Three measurements were taken and recorded by the research assistants. The two closest measurements within $0.1 \mathrm{~kg}$ were averaged during the data entry process. If there were no two measurements within $0.1 \mathrm{~kg}$, all three measurements were averaged.

\section{Weight Classification}

Weight classification was stratified into percentiles by sex using the 2000 Centers for Disease Control and Prevention BMI-for-age growth charts for children 2-20 years. BMI is a ratio between height and weight and is calculated by dividing weight in $\mathrm{kg}$ by height ${ }^{2}$ in $\mathrm{m}^{2}\left(\mathrm{BMI}=\mathrm{kg} / \mathrm{m}^{2}\right)$. Underweight was classified as $<5^{\text {th }}$ percentile. Normal weight was classified as $\geq 5^{\text {th }}-84.9^{\text {th }}$ percentile. Overweight was classified as $\geq 85^{\text {th }}-94.9^{\text {th }}$ percentile and obese was classified as $\geq 95^{\text {th }}$ percentile.

\section{Analysis}

All analyses were carried out using SAS/STAT software, Version [9.2] of the SAS System for Windows. To eliminate the chance that data from the same child measured in 2009 and 2010 was included twice, only the data recorded for the 5-year-old children in 2009 was combined with the data from 3, 4, and 5-year-old children in 2010 forming the 2009/10 group. Only the data for Hispanic and Caucasian children were included in the analyses as the number of participants of all other ethnicity/race $(n=56)$ for all years combined provided an insufficient sample size for analysis. Descriptive statistics were used to summarize the prevalence of overweight and obese for gender, ethnicity, and type of preschool by year. A stepwise logistic regression analysis was used to investigate BMI classification, where BMI categories of overweight $\left(\mathrm{BMI} \geq 85^{\text {th }}-94.9^{\text {th }}\right.$ percentile $)$ and obese $\left(\mathrm{BMI} \geq 95^{\text {th }}\right.$ percentile) were collapsed into one group. All covariates (gender, ethnicity, type of preschool), including year, and all twoway interactions were entered into the starting model. Logistic regression analysis was then used to further investigate two dependent variables: (1) overweight versus normal, and (2) obese versus overweight/normal. For each of these dependent variables, a separate logistic model was fit for each covariate (gender, 
Table 1

Demographic Characteristics and Logistic Model Results for Overweight vs. Normal Weight, and Obese vs. Overweight/Normal Weight.

\begin{tabular}{|c|c|c|c|c|c|c|}
\hline \multicolumn{3}{|l|}{$(\mathrm{n}=1041)$} & \multirow[t]{2}{*}{$\begin{array}{c}\text { Overweight } \\
\mathrm{n}(\%)\end{array}$} & \multirow[t]{2}{*}{$\begin{array}{l}\text { Obese } \\
\mathrm{n}(\%)\end{array}$} & \multirow{2}{*}{$\begin{array}{c}\begin{array}{c}\text { Overweight } \\
\text { p-value }\end{array} \\
0.0031\end{array}$} & \multirow{2}{*}{\begin{tabular}{r}
\multicolumn{1}{c}{$\begin{array}{c}\text { Obese } \\
\text { p-value }\end{array}$} \\
0.3056
\end{tabular}} \\
\hline Children & & & & & & \\
\hline \multirow[t]{2}{*}{ Overall } & 2006 & $\mathrm{n}=482$ & $62(12.9)$ & $65(13.5)$ & & \\
\hline & $2009 / 10$ & $\mathrm{n}=559$ & $107(19.1)$ & $88(15.7)$ & & \\
\hline Gender & & & & & $0.3904 \dagger$ & $0.6396 \dagger$ \\
\hline & & & & & $0.5543 \ddagger$ & $0.7900 \%$ \\
\hline \multirow[t]{2}{*}{ Boys } & 2006 & $\mathrm{n}=236$ & $34(14.4)$ & $30(12.7)$ & & \\
\hline & $2009 / 10$ & $\mathrm{n}=271$ & $53(19.6)$ & $42(15.5)$ & & \\
\hline \multirow[t]{2}{*}{ Girls } & 2006 & $\mathrm{n}=246$ & 28 (11.4) & $35(14.2)$ & & \\
\hline & $2009 / 10$ & $\mathrm{n}=288$ & $54(18.8)$ & $46(16.0)$ & & \\
\hline Ethnicity & & & & & $0.1681 \dagger$ & $0.0016 \dagger$ \\
\hline \multirow{3}{*}{ Caucasian } & & & & & $0.2038 \div$ & $0.0233 \$$ \\
\hline & 2006 & $\mathrm{n}=217$ & $28(13.0)$ & $27(12.4)$ & & \\
\hline & $2009 / 10$ & $\mathrm{n}=270$ & $46(17.0)$ & $25(9.3)$ & & \\
\hline \multirow[t]{2}{*}{ Hispanic } & 2006 & $\mathrm{n}=265$ & $34(12.8)$ & $38(14.3)$ & & \\
\hline & $2009 / 10$ & $\mathrm{n}=289$ & $61(21.1)$ & $63(21.8)$ & & \\
\hline Type of & & & & & $0.1274 \dagger$ & $0.0009 \dagger$ \\
\hline Preschool & & & & & $0.0816 t$ & $0.6129 \$$ \\
\hline \multicolumn{7}{|l|}{ Head Start } \\
\hline & 2006 & $\mathrm{n}=128$ & $21(16.4)$ & $22(17.2)$ & & \\
\hline & $2009 / 10$ & $\mathrm{n}=146$ & $61(21.1)$ & $63(21.8)$ & & \\
\hline \multicolumn{7}{|l|}{ CA State } \\
\hline & 2006 & $\mathrm{n}=206$ & $20(9.7)$ & $29(14.1)$ & & \\
\hline & $2009 / 10$ & $\mathrm{n}=180$ & $39(21.7)$ & 35 (19.4) & & \\
\hline \multirow[t]{2}{*}{ Private } & 2006 & $\mathrm{n}=148$ & $21(14.2)$ & $14(9.5)$ & & \\
\hline & $2009 / 10$ & $\mathrm{n}=233$ & 37 (15.9) & $21(9.0)$ & & \\
\hline
\end{tabular}

Logistic model includes the covariate, year, and the covariate by year as an interaction term.

The p-value for year is reported only one time.

$\uparrow$ indicates p-value for covariate

$\$$ indicates $\mathrm{p}$-value for covariate by year interaction

ethnicity, type of preschool), which included year and the covariate by year interaction. Model terms with p-values less than 0.05 were considered significant.

\section{Results}

Demographic characteristics of the sample and BMI classifications (overweight and obese) by year and covariate are shown in Table 1 . The mean age of children in the sample was 4.1 years $( \pm 0.70)$. In $2006,26.4 \%(\mathrm{n}=482)$ of children were OW/OB and in 2009/10, 34.8\% (n = 559) were OW/OB $(\mathrm{p}=0.007)$. Forty-nine percent of surveyed children were girls and 51\% boys, with 53\% Hispanic and $47 \%$ Caucasian children. Approximately $37 \%$ of children in the study attended California State preschools, 37\% attended private preschools while $26 \%$ attended Head Start preschools. Seventy-eight percent, 
Table 2

Adjusted Odds Ratios for Overweight and Obesity by Year, Ethnicity and Type of Preschool

\begin{tabular}{|c|c|c|c|c|}
\hline$(\mathrm{n}=1041)$ & & & $\begin{array}{c}\text { Adjusted Odds } \\
\text { Ratio (CI) of Being } \\
\text { Overweight }\end{array}$ & $\begin{array}{c}\text { Adjusted Odds Ratio } \\
\text { (CI) of } \\
\text { Being Obese } \\
\end{array}$ \\
\hline \multicolumn{5}{|l|}{ Children } \\
\hline \multirow[t]{2}{*}{ Overall } & 2006 & $\mathrm{n}=482$ & & \\
\hline & $2009 / 10$ & $\mathrm{n}=559$ & $\begin{array}{c}1.7(1.19,2.38) \\
\text { vs. } 2006\end{array}$ & \\
\hline \multicolumn{5}{|l|}{ Ethnicity } \\
\hline \multirow[t]{2}{*}{ Caucasian } & 2006 & $\mathrm{n}=217$ & & \\
\hline & $2009 / 10$ & $\mathrm{n}=270$ & & \\
\hline \multirow[t]{2}{*}{ Hispanic } & 2006 & $\mathrm{n}=265$ & & \\
\hline & $2009 / 10$ & $\mathrm{n}=289$ & & $\begin{array}{c}2.7(1.68,4.57) \\
\text { vs. Caucasian }\end{array}$ \\
\hline \multicolumn{5}{|l|}{$\begin{array}{l}\text { Type of } \\
\text { Preschool }\end{array}$} \\
\hline \multirow[t]{3}{*}{ Head Start } & & & & $\begin{array}{c}2.5(1.57,4.00) \\
\text { vs. Private }\end{array}$ \\
\hline & 2006 & $\mathrm{n}=128$ & & \\
\hline & $2009 / 10$ & $\mathrm{n}=146$ & & \\
\hline \multirow[t]{3}{*}{ CA State } & & & & $\begin{array}{c}2.0(1.31,3.17) \\
\text { vs. Private }\end{array}$ \\
\hline & 2006 & $\mathrm{n}=206$ & & \\
\hline & $2009 / 10$ & $\mathrm{n}=180$ & & \\
\hline \multirow[t]{2}{*}{ Private } & 2006 & $\mathrm{n}=148$ & & \\
\hline & $2009 / 10$ & $\mathrm{n}=233$ & & \\
\hline
\end{tabular}

$81 \%$, and $7.4 \%$, respectively, of participating Head Start, California State and private preschool children were Hispanic.

In the stepwise logistic regression analysis of BMI classification, the year by gender interaction $(\mathrm{p}=0.9479)$ was dropped in step 1 ; the ethnicity by type of preschool interaction ( $\mathrm{p}$ $=0.8993$ ) was dropped in step 2 ; the ethnicity by gender interaction $(\mathrm{p}=0.8947)$ was dropped in step 3 ; the gender by type of preschool interaction $(\mathrm{p}=0.6564)$ was dropped in step 4; gender $(p=0.7031)$ was dropped in step 5; and finally, the year by type of preschool interaction $(\mathrm{p}=0.4105)$ was dropped in step 6. The final model contained year $(\mathrm{p}=0.0041)$, ethnicity $(\mathrm{p}$ $=0.3607)$, type of preschool $(\mathrm{p}=0.420)$ and the year by ethnicity interaction $(\mathrm{p}=0.0293)$. The final model fit the data best, with a minimum
Akaike Information Criterion (AIC), and the Hosmer-Lemeshow test indicated no significant lack of fit to the data $(\mathrm{p}=0.9995)$. With a significant difference in obesity rates among the types of preschools, it was found that children enrolled in Head Start schools were 1.7 times more likely $(95 \% \mathrm{CI}=1.11,2.62)$ to be OW/OB than children enrolled in private preschools. However, there were no differences in the likelihood of OW/OB in children enrolled in California State preschools, than either children enrolled in private $(\mathrm{OR}=1.3,95 \% \mathrm{CI}=0.87$, $2.01)$, or Head Start schools $(\mathrm{OR}=0.8,95 \% \mathrm{CI}$ $=0.93,1.80)$. Note that $78 \%$ and $81 \%$ respectively, of surveyed Head Start and California State preschool children were Hispanic, while only $7.4 \%$ of surveyed private preschool children were Hispanic. Further investigation of the year by ethnicity interaction 
shows that in 2006, Hispanic children were no more likely to be OW/OB than Caucasian children, however, by 2009/10, Hispanic children were 1.6 times more likely $(95 \% \mathrm{CI}=$ $1.04,2.51)$ to be $\mathrm{OW} / \mathrm{OB}$ than Caucasian children (Figure 1).

The logistic regression analysis of the dependent variable overweight shown in Table 1 , found a significant difference in the proportion of overweight versus normal weight children only between years $(p=0.0031)$. In 2009/10, children were 1.7 (95\% CI: 1.19, 2.38) times more likely to be overweight than in 2006 (Table 2). No other significant differences were found.

The logistic regression analysis of the dependent variable obese versus overweight/normal found significant differences among the types of preschools $(p=0.0009)$. Children attending California State and Head Start preschools were 2.0 (95\% CI: 1.31, 3.17), and 2.5 (95\% CI: 1.57 , 4.00) times more likely, respectively, to be obese than children attending private preschools. Head Start preschool children were no more likely to be obese than children attending California State preschools. A significant interaction between year and ethnicity $(\mathrm{p}=$ 0.0233) was also found for obese. In 2006, Hispanic children were no more likely to be obese than Caucasian children, however, by 2009/10 Hispanic children were 2.7 times more likely $(95 \% \mathrm{CI}=1.68,4.57)$ to be obese than Caucasian children (Table 2). No other significant differences were found $(p>0.05$ in all cases).

\section{Discussion}

This study was conducted within a fairly small, rural geographic county that includes financially and socially disparate populations. We present valuable information about the weight status of preschool aged children in San Luis Obispo County. In 2006, 26.4\% and in 2009/10, 34.8\% of SLO County preschool children were OW/OB compared to $33.6 \%$ of children ages $2-5$ years in California and almost $25 \%$ in the United States (Department of Health Services, 2008; Ogden,
Carroll, Curtin, Lamb \& Flegal, 2010). The proportion of SLO County preschool children who were overweight or obese increased by $32.3 \%$ between 2006 and 2009/10, and Hispanic children and those who attended Head Start and California State preschool programs were disproportionately affected. This disparity has emerged over a very short period of time. In 2006 Hispanic preschoolers were no more likely to be OW/OB than Caucasian preschoolers, but by $2009 / 10$ were 2.7 times more likely to be obese. It is important to note that nearly all the Hispanic children $(92.6 \%)$ in our sample attended Head Start and California State preschools that require income eligibility for enrollment, while Caucasian children were more likely to attend private preschools. This fact exerted a strong influence on the differences in $\mathrm{OW} / \mathrm{OB}$ rates found among the different types of schools. Compared to private schools, Head Start preschool children were 2.5 times more likely to be obese, while those attending California State preschools were twice as likely.

One limitation of the study is the fact that teachers, not parents, reported race/ethnicity of the child. However, given the close relationship these pre-school teachers had with the families and the fact many speak Spanish, it is reasonable to believe race/ethnicity were properly identified.

The early development of weight-related health risk factors in overweight and obese children (Barton, Gilbert, Baramee \& Granger, 2006; Diamont, Babey, Wolstein \& Jones, 2010), and the strong relationship between high childhood BMI and excess bodyweight in young adulthood (Brisbois, Farmer \& McCargar, 2011) are of great concern on many fronts. Not only do we have an immediate public health crisis on our hands, but also the foreseeable future for these children and their families will be impacted unless we are able to quickly and successfully intervene.

Our findings are consistent with others and suggest a considerable ethnic/racial disparity in obesity rates in children (Anderson \& Whitaker, 2009; Wang \& Beydoun, 2007). The impact 
race/ethnicity, socioeconomic status, or a host of modifiable factors such as dietary patterns, physical activity, sleep and stress may play in this scenario need to be better understood as they relate to the development of overweight and obesity in young children. On a positive note, these findings also offer a window of opportunity for intervention, since we now have identified a specific vulnerable population (Hispanic preschoolers and their families) and location (Head Start and California State preschools) to target.

This study was a cross-sectional assessment of BMI among $\sim 25 \%$ of the county's preschoolers. Plans for the 2013 county assessment include systematic efforts to include a greater number of preschool children, including a stronger representation of private preschools and home schooled children. Longitudinal studies beginning at age three would identify how early in life overweight and obesity occurs in San Luis Obispo County, and the factors associated with shifts in BMI between the ages of $3-5$ years.
To insure that optimal quality of life becomes a reality for all children, tackling the complexity of the obesity epidemic requires we intervene simultaneously in each aspect of the environment - the home, school, community and understand how to best support the needs of different populations. Policy development within the county can facilitate and support the personal behaviors required for a healthy life, including sound nutrition and physical activity habits. Preschools can play a vital role in improving the physical health, and cognitive and socialemotional development of children through the environment provided on a daily basis. This includes decisions about the food and beverages provided, and providing an environment that increases physical activity and decreases time spent sedentary. Culturally appropriate and effective interventions designed to meet the needs of populations disproportionately affected by OW/OB in childhood are imperative. In our population, Head Start and California State preschools seem to offer the logical site for such interventions.

\section{References}

Anderson, S.E. \& Whitaker, R.C. (2009). Prevalence of obesity among US preschool children in different racial and ethnic groups. Archives of Pediatrics \& Adolescent Medicine, 163(4), 344-348.

Barton, A.J., Gilbert, L., Baramee, J. \& Granger, T. (2006). Cardiovascular risk in Hispanic and nonHispanic preschoolers. Nursing Research, 55(3), 172-179.

Brisbois, T.D., Farmer, A. P., \& McCarger, L.J. (2011). Early markers of adult obesity: a review. Obesity Reviews, doi: 10.1111/j.1467-789X.2011.00965.x

California Head Start Association. Retrieved from: http://caheadstart.org/HSPrograms.html

Department of Health Services, Children's Medical Services Branch, CHDP Program (2008). Pediatric Nutrition Surveillance System (PedNSS) 2007 Data Tables. Retrieved 11/06/08from http://www.dhcs.ca.gov/services/chdp/Pages/PedNSS2007.aspx

Diamant, A.L., Babey, S.H., Wolstein J. \& Jones M. Obesity and Diabetes: Two Growing Epidemics in California. Los Angeles, CA: UCLA Center for Health Policy Research, 2010.

First 5 Preschool. Retrieved from: http://www.slocoe.org/education/preschool/home/preschoolsites.html Let's Move. Retrieved from: http://www.letsmove.gov

Must, A., Spadano, J., Coakley, E.H., Field, A.E., Colditz, G. \& Dietz, W.H. (1999). The disease burden associated with overweight and obesity. Journal of the American Medical Association, 282(16), 1523-1529.

Ogden, C. L., Carroll, M. D., Curtin, L. R., Lamb, M. M., \& Flegal, K. M. (2010). Prevalence of high body mass index in U.S. children and adolescents, 2007-2008. Journal of the American Medical Association, 91(3), 519-527.

Ogden, C. \& Carroll, M. (2010). Prevalence of obesity among children and adolescents: United States, trends 1963-1965 through 2007-2008. National Center for Health Statistics, Centers for Disease 
and Prevention, June 2010. Retrieved from:

www.cdc.gov/nchs/data/hestat/obesity_child_07_08/obesity_child_07_08.pdf

Poirier, P., Giles, T.D., Bray, G.A., Hong, Y., Stern, J.S., Pi-Sunyer, F.X. \& Eckel, R.H. (2006). Obesity and cardiovascular disease: Pathophysiology, evaluation, and effect of weight loss: An update of the 1997 American Heart Association Scientific statement on obesity and heart disease from the Obesity Committee on the Council on Nutrition, Physical Activity, and Metabolism. Circulation, 113, 898-918.

Singh, G.K., Kogan, M.D. \& van Dyck, P.C. (2010). Changes in state-specific childhood obesity and overweight prevalence in the United States from 2003-2007. Archives of Pediatrics and Adolescent Medicine, 164(7): 598-607.

Tom, K., Rivera, M., Ravalin, D., \& Jankovitz, K. (2009). Prevalence of obesity among San Luis Obispo County preschool children [Abstract]. 2009 abstract submissions. Retrieved from http://www.swacsm.org/annual-meeting.htm

U.S. Census Bureau, 2005-2009 American Community Survey. Available at: http://factfinder.census.gov/servlet/ADPTable?_bm=y\&geo_id=05000US06079\&qr_name=ACS _2009_5YR_G00_DP5YR2\&-gc_url=\&-ds_name=\&-_lang=en\&-redoLog=false

U.S. Department of Health \& Human Services Healthy People 2020 (October 30, 2009). NWS HP2020-5, HP2020-15. Retrieved from: http://www.healthypeople.gov/hp2020/objectives/ViewObjective.aspx?Id=277\&TopicArea=Nutri tion+and+Weight + Status $\&$ Objective $=$ NWS + HP2020\%E2\%80\%935\&TopicAreaId $=35$

U.S. Department of Health \& Human Services, National Center for Chronic Disease Prevention and Health Promotion, Division of Adolescent and School Health (September 15, 2011).

Retrieved from: www.cdc.gov/healthyyouth/obesity/facts.htm

Author Information

*Kristine Z. Jankovitz, PhD

California Polytechnic State University

Department of Kinesiology

San Luis Obispo, CA 93407-0386

TEL: 805 756-2534

FAX: 805 756-7273

email:kjankovi@calpoly.edu

Karen J. McGaughey, PhD

California Polytechnic State University

San Luis Obispo, CA

Dayna Ravalin, RD, CDE

County Public Health Department

San Luis Obispo, CA

Kyla Tom, MS

California Polytechnic State University

San Luis Obispo, CA

Ann Yelmokas McDermott, PhD, MS, LDN

California Polytechnic State University

San Luis Obispo, CA

* corresponding author 